\title{
Elderly readmission prevalence and related factors in educational hospitals
}

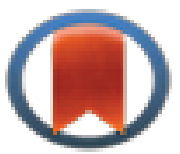

CrossMark

dick for updates

in Bojnurd, April-May 2017

Jahani $\mathrm{A}^{1}$, *Tayebi $\mathrm{V}^{2}$, Hares Abadi $\mathrm{M}^{3}$, Taher Pour $\mathrm{M}^{4}$

1- MSc Student in Eldemsc, North Khorasan University of Medical Sciences, Bojnurd, Iran.

2- Faculty Member, North Khorasan University of Medical Sciences, Bojnurd, Iran (Correspondent Author)

E-mail: vi_tay@yahoo.com

3- Faculty Member, North Khorasan University of Medical Sciences, Bojnurd, Iran.

4- Faculty Member, North Khorasan University of Medical Sciences, Bojnurd, Iran.

\section{Abstract}

Introduction: Elderly re-admission to the hospital is a recurrent, costly and often life-threatening event. This study has been performed with the aim of assess the prevalence and factors associated with elderly readmission.

Method: The present study is a descriptive-analytic study with cross-sectional method which was done through convenience sampling. The study was done on a total of 441 elderly who were eligible for entering the study and discharged from three hospitals in Bojnourd in April-May 2017. Data gathering tool was a researcher-made questionnaire that its reliability is calculated with Cronbach's alpha coefficient 0.86 and face and content validity was approved by ten faculty members in geriatric nursing department. The questionnaire was completed in three stages: From May 1 for a month daily, then at the end of a month and three months after the discharge of each patient. Data was collected using information obtained from the patient himself or his companions also by referring to the information in the HIS system and patient records. Data interpretation was done using SPSS-21.

Results: The majority of sample (56\%) were female, (67\%) aged 60-75 years old, (64.5\%) married, (52\%) lived in the city, (56\%) had independent income, (74\%) illiterate, (45\%) and lived with children 45 of the discharged elderly $(\% 10.2)$ had a re-admission within one month and within three months after the discharge was 61 people (\%13.8). The results of the findings are based on chi-square test showed a significant relationship between the elderly dependency status and re-admission $(\mathrm{p}<0 / 01)$. There was no significant relationship for other factors such as demographic and clinical variables as well as environmental- hospital variables with elderly readmission ( $\mathrm{p} \geq 0 / 05)$.

Conclusion: Elderly patients who have a level of dependency on their relatives, more likely to be re-admitted. Paying attention to the dependence of the elder on relatives; to meet their basic needs; serves as a prevention of their subsequent sequelae and re-hospitalization.

Keywords: re-hospitalization, readmission, elderly.

\begin{tabular}{|l|l|}
\hline \multicolumn{3}{|c|}{ Access this article online } \\
\hline
\end{tabular}


بررسى شيوع و عوامل مرتبط با بسترى شدن مجدد سالمندان در بيمارستان هاى منتخب آموزشى

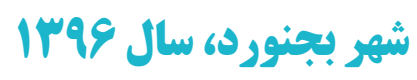

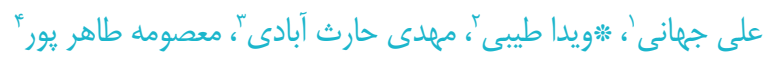

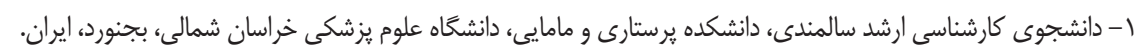

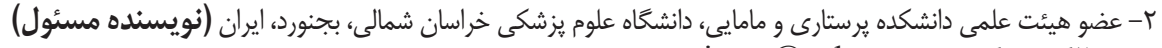
vi_tay@yahoo.com يست الكترونيكى

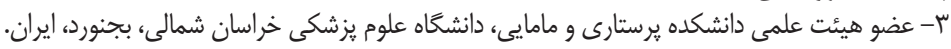

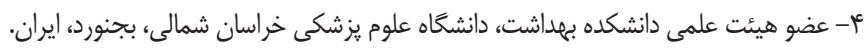

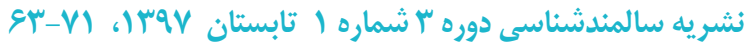

\section{جكيله}

مقدمه: بسترى مجدد در سالمندان، يك رويداد تكرار يذير، ير هزينه و اغلب يك فاكتور ييشگويى كننده تهديد حيات مى باشد. مطالعه حاضر به منظور بررسى شيوع بسترى مجدد و عوامل مرتبط با آن انجام شد.

روش: يثوهش حاضر يك مطالعه توصيفى- تحليلى از نوع مقطعى است كه از طريق نمونه گيرى آسان صورت گرفت. از از ابتداى ارديبهشت ماه عهسا، أعأ سالمند ترخيص شده از سه بيمارستان آموزشى شهر بجنورد؛ داراى شرايط ورود به مطالعه؛ به عنوان نمونه در

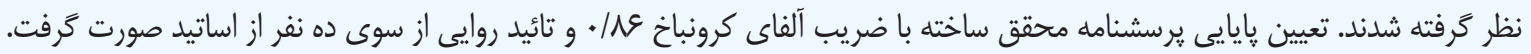

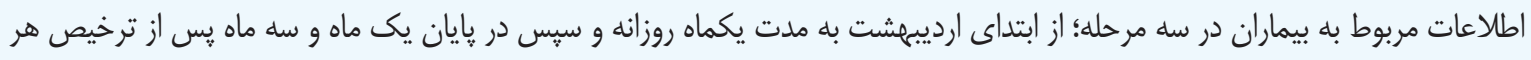

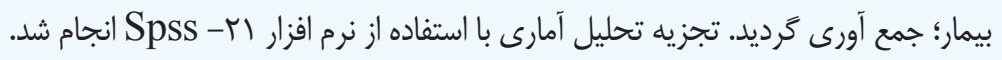

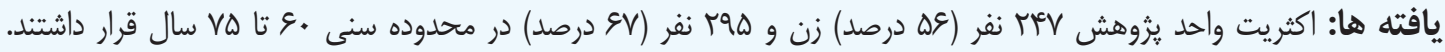
همجنين ع

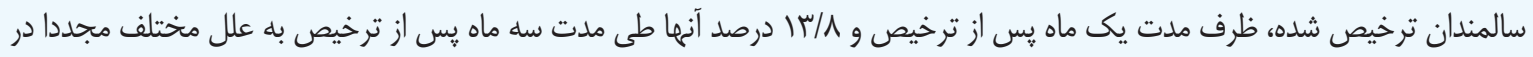

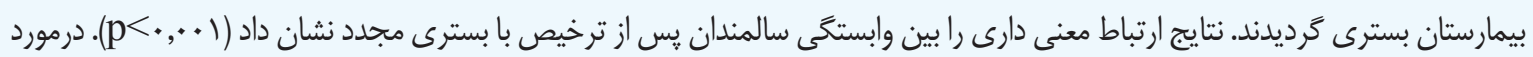

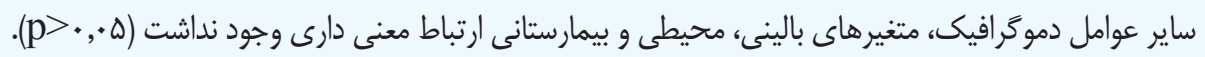
نتيجه كَيرى: سالمندان ترخيص شده كه جهت فعاليت هاى روزانه به همراهان خود وابسته هستند، احتمال بسترى شدن مجدد بيشترى دارند. توجه به امر وابستخى بيمار به همراهان جهت رفع نيازهاى يايه، به منزله يبشخيرى از تبعات بعدى و بسترى شدن مجدد وىى مى باشد. كليد وازه ها: شيوع، بسترى مجدد، سالمند. 
عنوان نموده و بيان كردند كه اين مسئله مى تواند حاكى از درمان ناقص، عدم رعايت يروتكل هاى درمانى و استاندارد نبودن امكانات بيمارستانى باشد و اين مراجعات مجدد باعث افزايش اقامت بئ بيماران

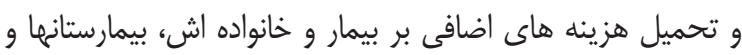

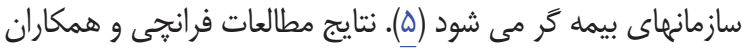

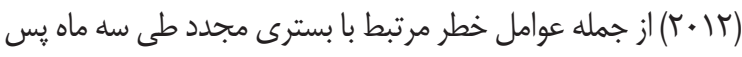
از ترخيص را وجود مشكلات قلبى، عروقى و بيماريهاى كبدى عندئ عنوان

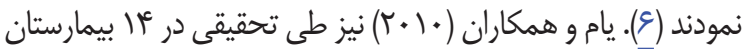

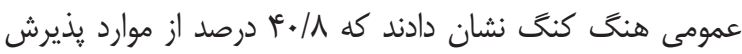
مجدد بيمارانى كه درعرض يكماه يس از ترخيص يذيرش مجدد يِيش بينى نشده داشتند، قابل اجتناب بوده است (V). نتايج مطالعاله

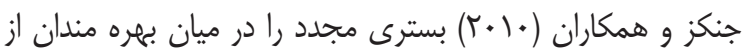
مزاياى بيمه اى امرى شايع و ير هزينه عنوان نموده و متوسط اقامت

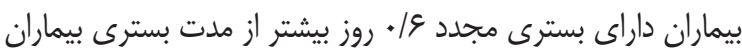
ديخر با همان تشخيص يزشكى ذكر كردند. هارماراجان و همكاران بران (T.IV)

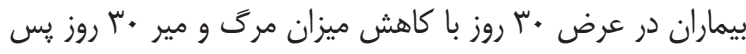

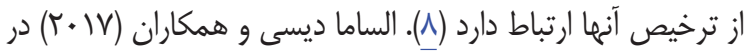

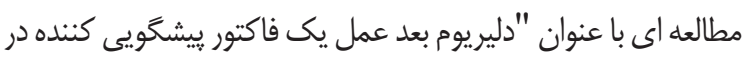

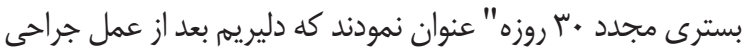

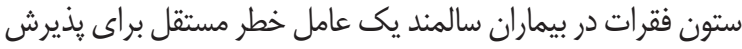

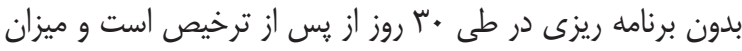

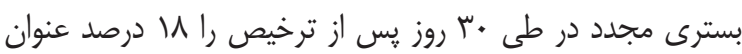

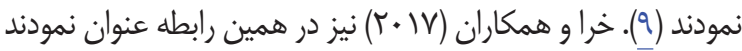

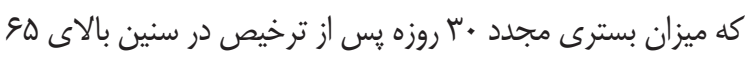

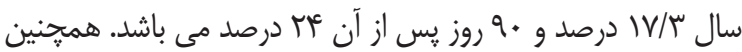

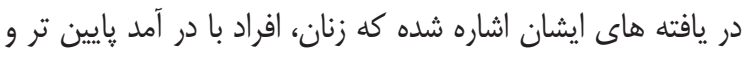
محدوده سنى كمتر، به ميزان بيشترى در خطر بسترى مجدد قرار

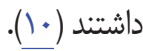

بر اساس يافته هاى مطالعات فوق، بسترى مجدد در سالمندان با افزايش سطح ناتوانى و ناخوشى و وابستخى هرجّه بيشتر سالمندان همراه بوده كه سبب افزايش اقامت بيماران و تحميل هزينه هاى

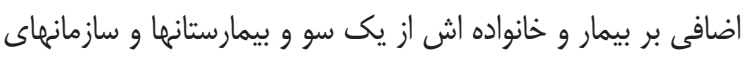

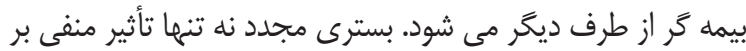

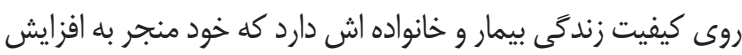
بار بيماريها و اثرات اقتصادى نامطلوب برسيستم ارايه دهنده مراقبت

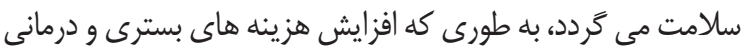

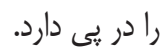
در استان خراسان شمالى مطالعاتى كه مولفه هاى تاثير گذار بر

\section{مقاله do}

سالمندى بديده اي جهانى است. از نظر سازمان جهانى بهداشت، سالمندى به جمعيت بالاى •ع سال اطلاق مى گرىدد. در

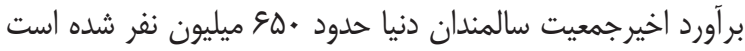

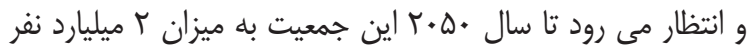
برسد (ا). ايران نيز به عنوان يكى از كشورهاى در حال توسعه از اين اين تغييرات جمعيتى مستثنى نيست. بر اساس سر شمارى سال هوسبا،

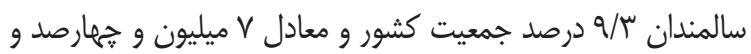
ينجاه هزار نفر برآورد شده اند. تخمين زده شده كه تا سال ... If

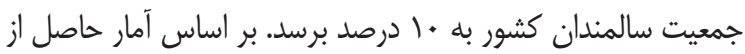

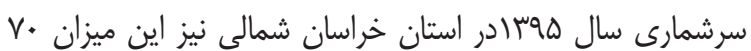
هزار سالمند معادل / / درصد نسبت جمعيت استان را سالمندان

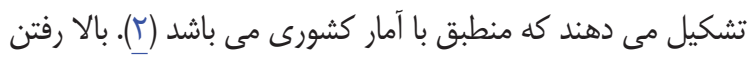
سن و رسيدن به دوران سالمندى، توانايى هاى عملكردى و قدرت حواس را كاهش و خطر بيمارى ها را افزايش مى دهد. از آنجا كه نياز عمده زنان و مردان سالمند در درجه اول بهداشت و واش سلامتى است، بيرشدن جمعيت در بسيارى از كشورها تقاضا براى دريافت خدمات

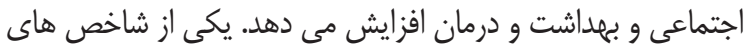
افزايش دريافت خدمات، ازدياد مصرف منابع بيمارستانى در بسترى مجدد است. مى توان كفت نرخ بسترى مجدد يك شاخص مفيد از

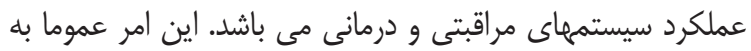

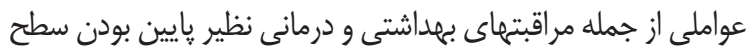
بهداشت و خدمات اجتماعى مرتبط مى باشد كه آن را مى توان بان بهان بهان

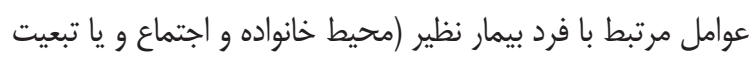
از رزيم درمانى) و يا عوامل مربوط به نوع بيمارى نظير (ييشرفت

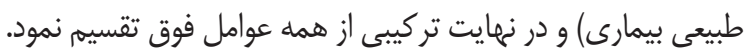

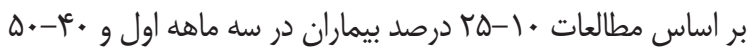

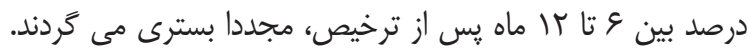

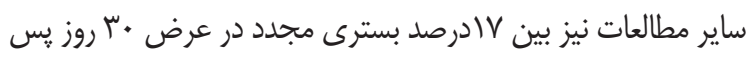
از ترخيص و برخى ديكر 19 درصد را تا سه ماه بعد از آن ذكر كرده

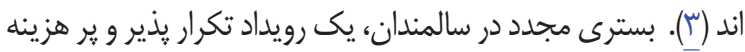

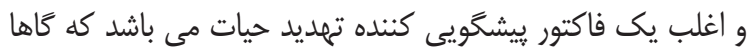

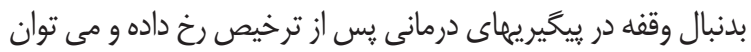

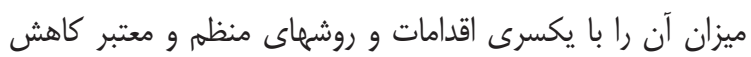
داد. از طرفى، بسترى مجدد يك شاخص مفيد براى تعيين عملكرد إن إنات

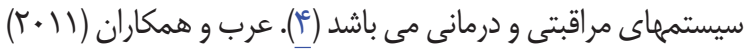

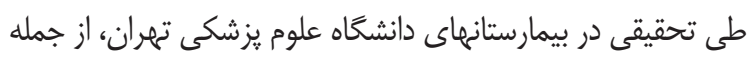

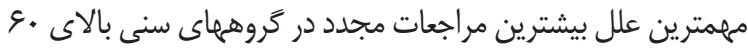

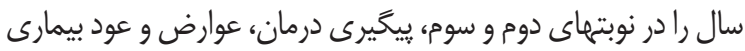


عفونى، قلب، Icu g ccu بيمارستان هاى منتخب آموزشى شهر بجنورد (بيمارستانهاى امام رضا (ع)، امام على (ع) و ثامن الائمه

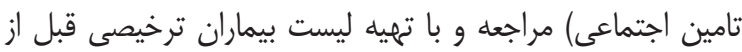
خروج بيمار قسمتى از اطلاعات مورد نياز يرسشنامه شماره يك فيك

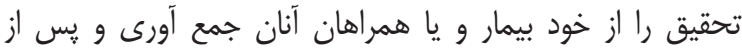
آن با توجه به اطلاعات موجود در سيستم HIS و و يرونده بيمار

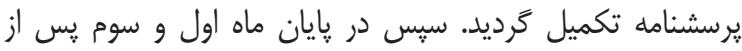

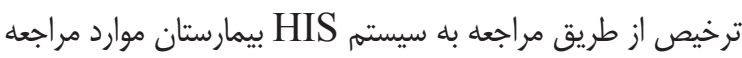
مجدد را استخراج و از يرونده موجود در بايكانى اطلاعات مورد نياز

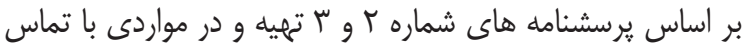

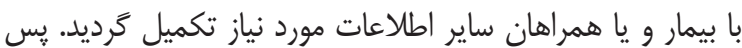
از كرد آورى دادهها، جهت تجزيه تحليل وارد نرم افزار آب-SpSS كرديده، شاخصهاى آمار توصيفى ميانگين ميانكين، ميانه انحراف معيار، جداول توزيع فراوانى، جداول توافقى و درصد ها مورد تجزيه و و

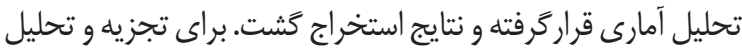

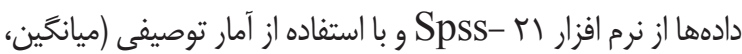

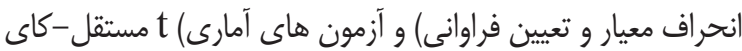

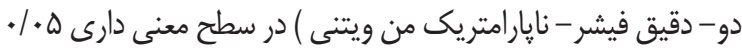
و ضريب اطمينان هو٪ استفاده شد.

جهت رعايت ملاحظات اخلاقى، اين طرح تحقيقاتى با

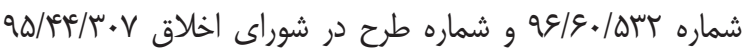
در دانشكاه علوم يزشكى خراسان شمالى مورد تصويب قرار گرَفت و رضايت سالمندان جهت شركت در مطالعه مورد توجه قرار كرفت ودر ورد خصوص اهداف يثوهش و محر مانه ماندن اطلاعات توضيح داده شد.

\section{كإْته ونا}

در اين مطالعه اكثريت بيماران VأT نفر (وه درصد) زن، هوج

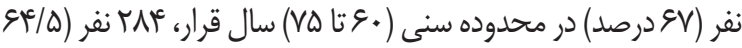

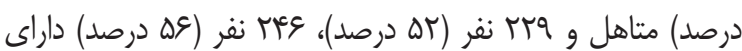
در آمد مستقل و وبr نفر ( از آزمون كاى دو نشان داد كه بين وضعيت وجود همر اهان زندرّى درد بيماران سالمند ترخيص شده در ارديبهشت و بيماران سالمند بسترى مجدد يكى ماهه و سه ماهه پِ از ترخيص تفاوت آمارى معنى دارى

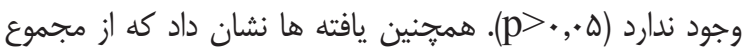

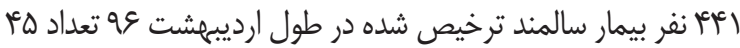
نفر بيمار سالمند معادل / / ا درصد، ظرف مدت كمتر از يكماه پِ از ترخيص و تعداد اوبيمار سالمند معادل ^/ آ درصد طى مدت سله ماه پٍ از ترخيص (تا بايان مرداد ماه عو) به علل مختلف مجدد به بيمارستان مراجعه و بسترى گرديده اند(جدول) (1).
بسترى شدن مجدد در سالمندان را نشان دهد، انجام نشده است. آمار

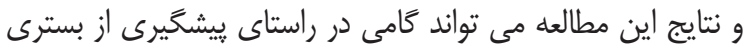
مجدد و افزايش بهره ورى و استفاده بهينه از منابع درمانى براى ارائه خدمات به اين قشر از جامعه استان قرار كيرد.

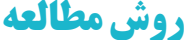

يزوهش حاضر يك مطالعه توصيفى - تحليلى از نوع مقطعى رونى بوده و از طريق نمونه گَيرى آسان (در دسترس) صورت كَرفت. كليه بيماران سالمند بالاى •و سال كه در ارديبهشت ماه عو از از بخشهاى داخلى، جراحى، عفونى، قلب، ccu و Icu بيمارستان هاى منتخب آموزشى شهر بجنورد (بيمارستانهاى امام رضا (ع)،

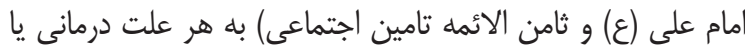

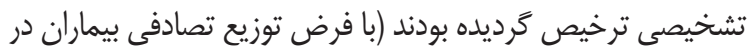

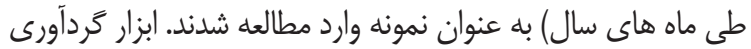
اطلاعات، يرسشنامه محقق ساخته بود كه اطلاعات، متغيرهاى دموًرافيك شامل (جنسيت، سن، تاهل، منطقه سكونت، وضعيت درآمد، تحصيلات، وجود همراهان (مراقبان) در زندكَى)، اطلاعات متغيرهاى بالينى شامل (بيمارى جديد، عوارض عمل جراحى، عفونت بعد عمل جراحى، درمان ناقص، شكست درمان، عود بيمارى، كروها هاى بيمارى، تعداد و نوع بيماريهاى همزمان) و اطالاعات متغيرهاى دراى محيطى و بيمارستانى شامل (نوع بخشماى خدمات دهنده، نوع بيمه درمانى، سابقه بسترى طى سه ماه قبل، هزينه خدمات پاراكلينيك، سطح وابستخى بيمار هنكام ترخيص، تعداد دفعات بسترى، طول مدت بسترى، فاصله زمانى از بسترى اوليه،

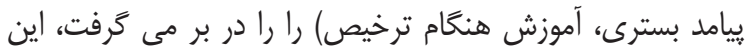

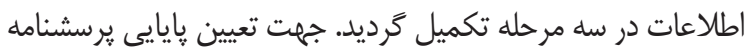

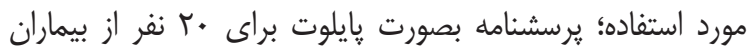
سالمند ترخيص شده از بيمارستان تكميل كرديد و مقدار ضريب

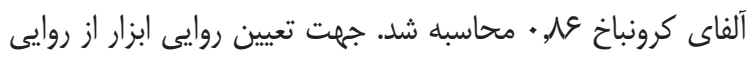

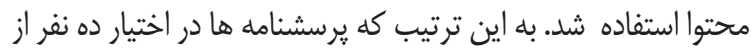

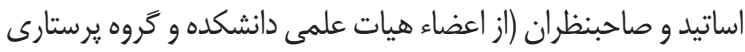
سالمندى) قرار كَرفته و پِّ از بحث و تبادل نظر و به كاركيّى نظرات و ييشنهادات اصلاحى اساتيد ير سشنامه نهايى تهيه و تنظيم

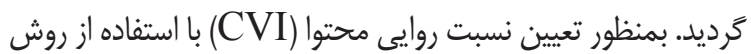

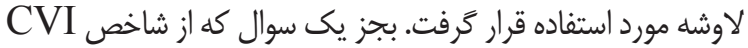
نمرهى كمتر از V9,·• را كسب نمود، بقيه سوالات نمره بـ بالاتر از

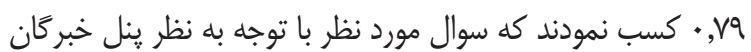
اصلاح شده و با سوال مناسب جايخزين كَديد. جهت جمع آورى اطلاعات يرسشنامه از اولين روز ماه ماه

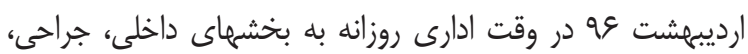


جدول (: توزيع فراوانى بيماران سالمند ترخيص شده در ارديبهشت عوو بسترى مجدد يس از يك ماه و سه ماه يس از ترخيص بر حسب سطح وابستكى بيمار هنكام

\begin{tabular}{|c|c|c|c|c|c|c|c|c|}
\hline \multicolumn{2}{|c|}{ نتيجه آزمون } & \multicolumn{2}{|c|}{ بسترى مجدد سه } & \multicolumn{2}{|c|}{ بسترى مجدد يك } & \multicolumn{2}{|c|}{ شالمندان ترخيص در ارديبهشت } & \multirow[t]{2}{*}{ وضعيت وابستگى } \\
\hline سه ماهد & يك ماهd & درصد & تعداد & درصد & تعداد & درصد & تعداد & \\
\hline$p=\cdot / \cdot r$ & $\mathrm{p}=\cdot / \cdot 1 \mu$ & M & 11 & re & 11 & שt & 119 & بدون وابستكى \\
\hline (آماره & ع & NT & $\omega$. & Ve & me & $\Delta V$ & TAT & داراى وابستخى عملكرد \\
\hline $\mathrm{Df}=r$ & $D f=r$ & $1 \ldots$ & 91 & $1 \ldots$ & id & $1 \ldots$ & pel & جمع \\
\hline
\end{tabular}

يافته ها ارتباط معنى دارى را (1 +., ••p) بين وابستخى بيمار عوامل موگر افيك، متغيرهاى بالينى، محيطى ارتباط معنى دارى وجود

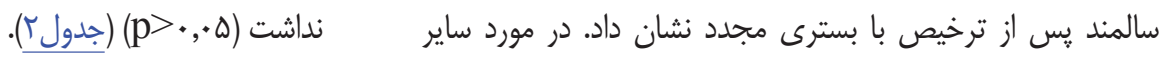

جدول ז: توزيع فراوانى بيماران سالمند ترخيص شده در ارديبهشت عqو بسترى مجدد پِ از يك ماه و سه ماه پِ از ترخيص بر حسب وجود همراه در زندكى (مراقبان)

\begin{tabular}{|c|c|c|c|c|c|c|c|c|}
\hline \multicolumn{2}{|c|}{ بسترى مجدد سه ماهd } & \multicolumn{2}{|c|}{ بسترى مجدد يك ماهـ } & \multicolumn{2}{|c|}{ بسترى مجدد يك ماهd } & \multicolumn{2}{|c|}{ شالمندان ترخيص در ارديبهشت } & \multirow{2}{*}{ زوجود همراه در } \\
\hline درصد & تعداد & درصد & تعداد & درصد & تعداد & درصد & تعداد & \\
\hline $\mathrm{p}=\cdot / \S \wedge \Delta$ & $\mathrm{p}=\cdot / 99)^{\circ}$ & M & שו & $T r / D$ & 1. & ME & $1 \cdot 0$ & تنها \\
\hline ه & 191 =•= آماره & r) & זו & $T \varphi / \Delta$ & 11 & in & 191 & با فرزندان \\
\hline \multirow[t]{2}{*}{ Df $=r$} & $\mathrm{Df}=r$ & $\Delta \wedge$ & מם & U & TE & ו & או & با همسر \\
\hline & & $1 \ldots$ & 91 & $1 \ldots$ & $i \Delta$ & $1 \ldots$ & 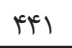 & جمع \\
\hline
\end{tabular}

نتايج حاصل از آزمون دقيق فيشر نشان داد كه ميان وجود درارديبهشت عq تفاوت آمارى معنى دارى وجود ندارد (ه+, •p)

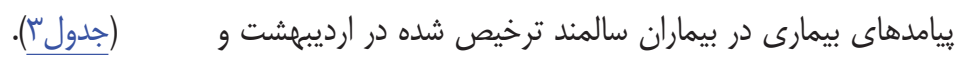
بيماران سالمند بسترى مجدد يك ماه و سه ماه يس از ترخيص

جدول ب: توزيع فراوانى يِيامد بسترى در بيماران سالمند ترخيص شده ارديبرشت عq و بسترى مجدد يس از يك ماه و سه ماه يس از ترخيص

\begin{tabular}{|c|c|c|c|c|c|c|c|c|}
\hline \multicolumn{2}{|c|}{ نتيجه آزمون } & \multicolumn{2}{|c|}{ بسترى مجدد سه } & \multicolumn{2}{|c|}{ بسترى مجدد يك } & \multicolumn{2}{|c|}{ شالمندان ترخيص در ارديبهشت } & \multirow[t]{2}{*}{ ييامد بيمارى } \\
\hline درصد & تعداد & مرصد & تعداد & درصد & تعداد & لر & تعداد & \\
\hline \multirow{7}{*}{ 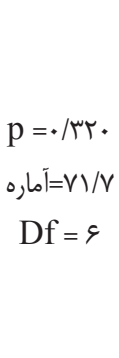 } & \multirow{7}{*}{$\begin{array}{c}\mathrm{p}=\cdot / \cdot 9 \mathrm{~V} \\
\text { ه }=\mathrm{T}=\mathrm{W} / \mathrm{s} \\
\mathrm{Df}=\varepsilon\end{array}$} & سז & 16 & $r$. & 9 & $\Delta$ & זr & عوارض موقت \\
\hline & & $\Delta$ & r & r & 1 & r & 11 & عوارض پايدار \\
\hline & & $\Delta / \kappa^{c}$ & r & $\Gamma / \Delta$ & r & $1 / \Delta$ & $\checkmark$ & نقص عضو \\
\hline & & $\Delta / \kappa$ & r & $\Gamma / \Delta$ & r & $\cdot 10$ & r & فوت \\
\hline & & ון & 19 & rq & זו & זם & IDF & بهبودى نسبى \\
\hline & & me & rI & f. & $M$ & $\Delta \Delta$ & سזו & بهبودى كامل \\
\hline & & $1 \ldots$ & 91 & $1 \ldots$ & $i \Delta$ & $1 \ldots$ & eq & جمع \\
\hline
\end{tabular}

آزمون دقيق فيشر نشان داد ميان وضعيت گروه بندى بيماريها در بيماران سالمند ترخيص شده و بيماران سالمند بسترى مجدد يك ليك ماه و سه ماه يس از ترخيص تفاوت آمارى معنى دارى وجود ندارد

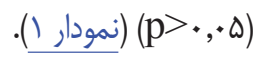

نتايج نشان داد كه بيماريهاى قلبى و عروقى با وج درصد در سالمندان ترخيص ارديبهشت و سع درصد (9 انفر) در بسترى مجدد يك ماهd و رץ درصد (ها نفر) در بسترى مجدد سه ماه يس از ترخيص بيشترى فراوانى را داشته اند. نتايج بدست آمده از 


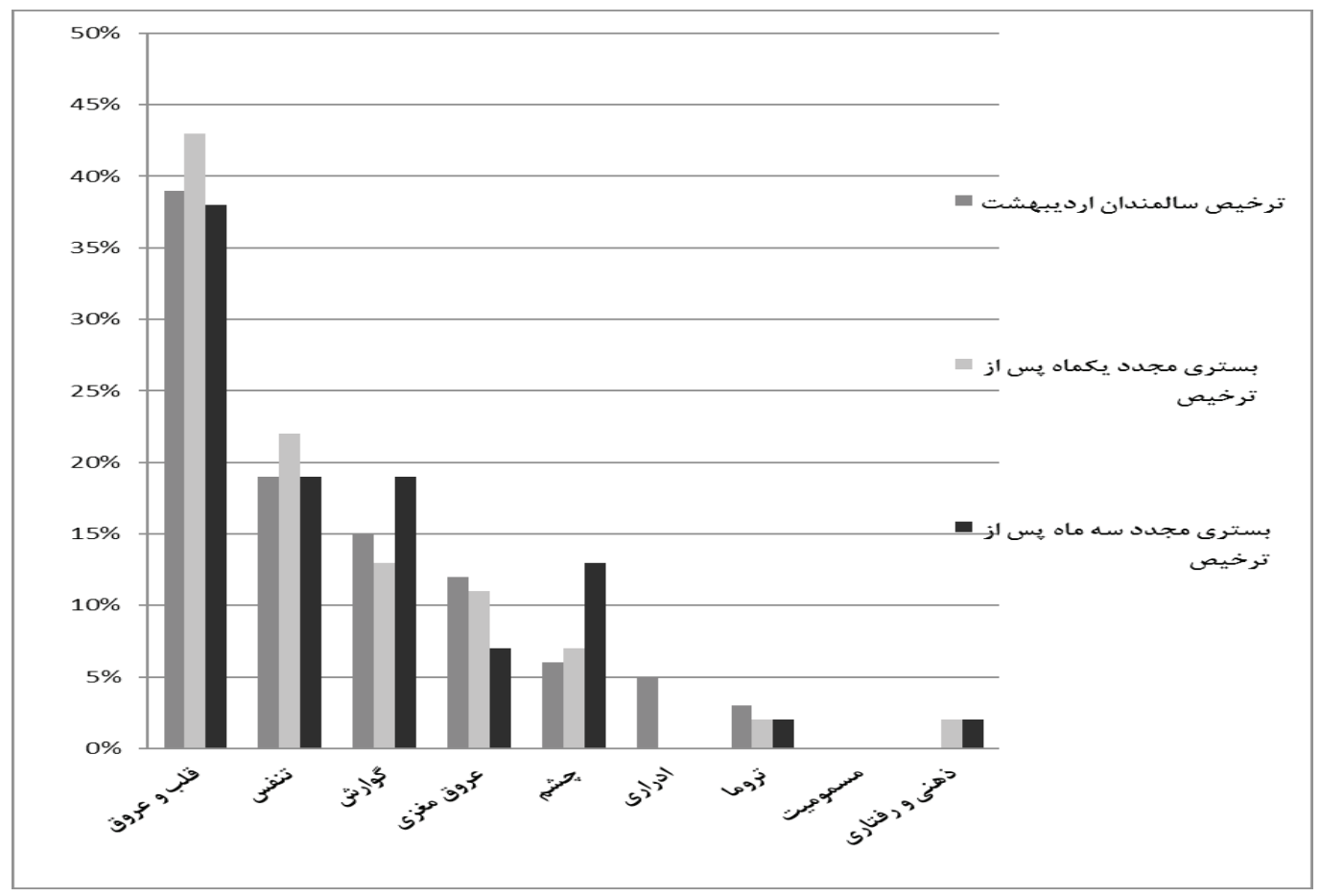

نمودار ا: وضعيت گَروه بندى بيمارى ها در بسترى مجدد يكماه و سه ماه پِ از ترخيص در مقايسه با ترخيص سالمندان در ارديبهشت وح بوده است (T).). مطالعه اى كه توسط زانوجى ع. +ب در بازه سه ماه ثحث

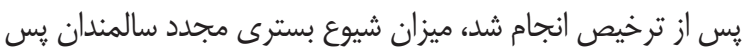

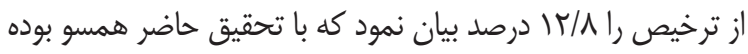

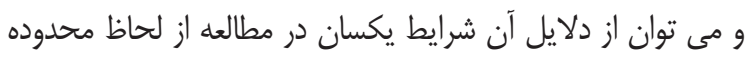

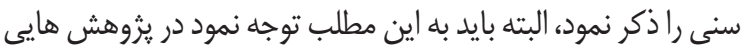
با موضوع بسترى مجدد كه محدوده سنى سالمندان (بالاى •9 سال)

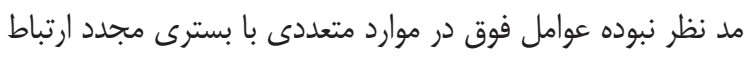

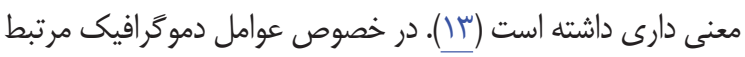
با بسترى مجدد همجيون سن، جنس، تاهل، منطقه سكونت، درآمد،

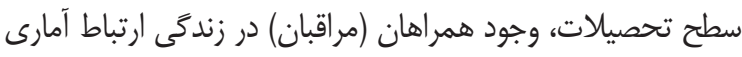

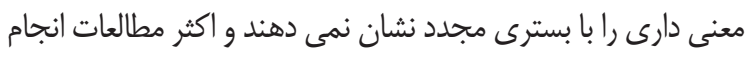
شده نيز در اين زمينه، نتايج مشابهى داشته اند، بطور نمونه حيدرى

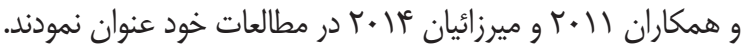
ارتباط معنى دارى ميان تاهل و محل سكونت با بسترى مجدد وجود

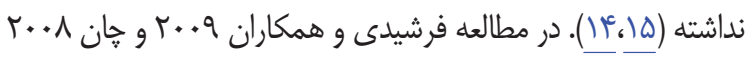
عدم ارتباط بين جنس و بسترى مجدد را بيان نموده بودند (IV، (IV). از نظر متغيرهاى محيطى و بيمارستانى از جمله بخشهاى خدمات

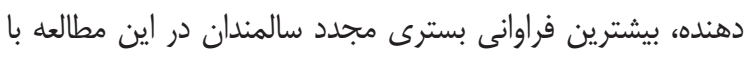

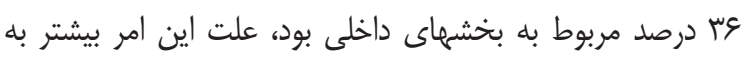

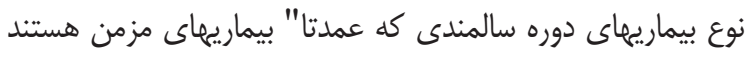

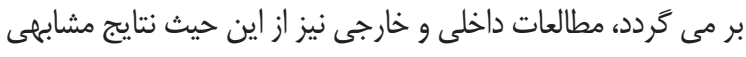
نتايج يزوهش نشان مى دهد كه فراوانى بسترى مجدد سالمندان در يكماه پِس از ترخيص r/. إ درصد و در بازه سه ماه

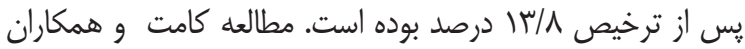

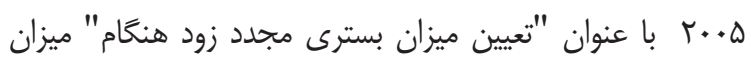

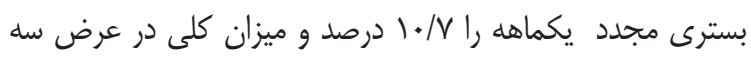
ماه ا/بr درصد كزارش كردند (11) كه اين نتايج در بازه بسترى مجدد يك ماه با تحقيق حاضر همسو بوده ولى در ميزان سه ماه با

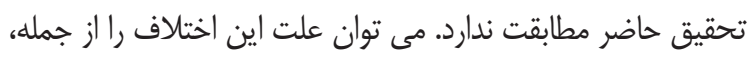

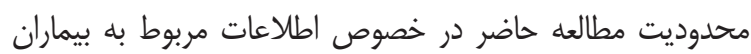
بسترى مجدد شده در ساير مراكز درمانى عنوان نمود به طورى

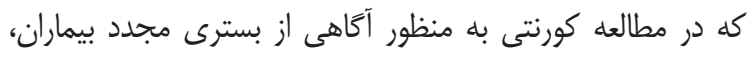

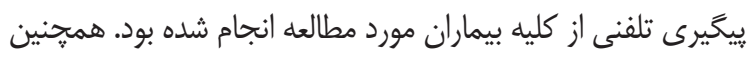

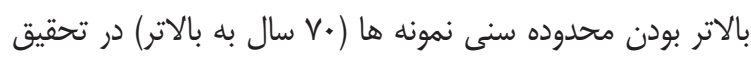
فوق مى تواند از علل ديخر افزايش نرخ بسترى مجدد سه ماه باشاه.

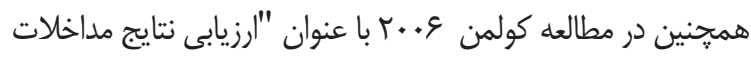

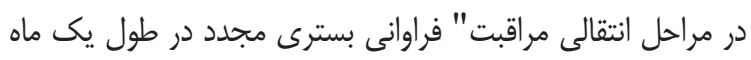

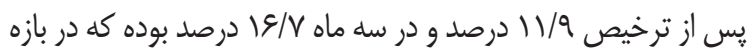
سه ماه با تحقيق حاضر مطابقت ندارد. از دلايل اين تفاوت مى توان، تعيين محدوديت براى سالمندان بسترى شده جهت ورود به مطالعه را ذكر نمود به طورى كه تنها سالمندان داراى مسكن مستقل مدنظر سند 
ييخيرى و ميزان تغيير مطلوب حاصل شده در نتيجه درمان، وضعيت سلامت و ساير شرايطى كه با آن مواجهند، نياز به آموزش و اطلاعات دارند و كسب هنين اطلاعاتى علاوه بر اينكه باعث جلب اطمينان

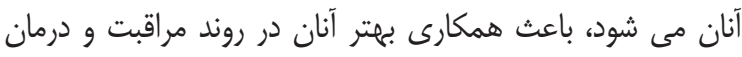
خواهد شد. اهميت ارائه اطلاعات به سالمندان بسترى در اين زمينه، طى يزوهش هايى روشن شده است (ع).

\section{تُتيجه تَيرى نُهائى}

بيماران سالمند ترخيص شده از بيمارستان كه جهت فعاليت هاى روزانه خود به همراهان وابسته هستند، احتمال بيشترى را براى بسترى شدن مجدد دارا مى باشند. بايد اين مطلب را به همر اهان بيمار

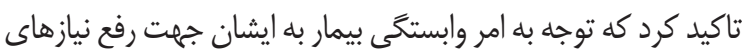

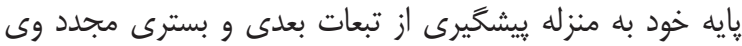

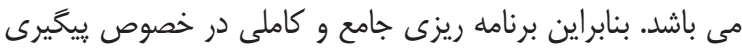
هاى پِ إز ترخيص از جانب سيستمهاى بهداشتى و درمانى

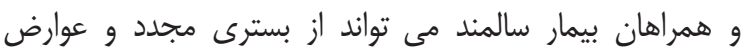
و ويامدهاى كاها غيرقابل جبران نظير عوارض و فوت يِيشخيرى

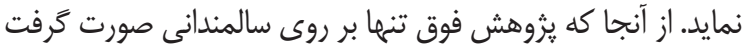

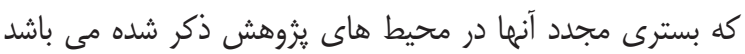

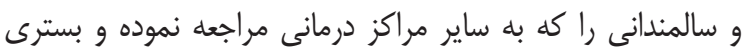
مجدد داشته اند را در بر نخرفته است، لذا جهت تعميم نتايج ييشنهاد مى كَردد كه مورد مذكور در يزوهش هاى آتى مد نظر قرار كيرد.

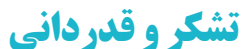

يزووهشكران مراتب تشكر و قدردانى خود رااز معاونت يزوهشى دانشكاه علوم يزشكى خراسان شمالى و همجنين معاونت آموزشى و يزوهشى دانشكده ي يرستارى و مامايى بجنورد، واحد تحقيقات و والى يزوهش سالمندى به خاطر تصويب و تأمين هزينه هاى طرح ابراز

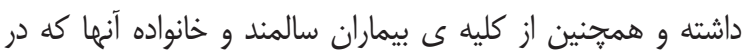
انجام اين ثروهش همكارى لازم را داشته اند سياسخزارى مى كَردد.

\section{References}

1. WHO | Definition of an older or elderly person. (accessed 8 august 2016).

2. Statistical Center of Iran (SCI) (accessed 8august2016).(http://nnt.sci.org.ir/sites/ nnt/SitePages/report_90/population_report. aspx)

3. Garcia-Perez L, Linertova R, Lorenzo-
را نشان مى دهند (1) همجنين مطالعه Mould-Q uevedo 9 . ب در مكزيك نشان داد كه M درصد از مجموع روز- بيمارها به بخشهاى داخلى تعلق داشته است (19). به لحاظ نوع بيمه درمانى،

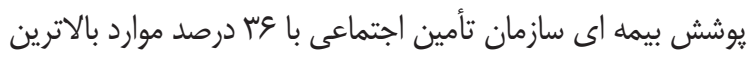

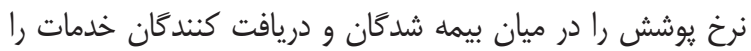
داشتند، اين نسبت با در نظر كرفتن بافت كلى جمعيت شهرستان بجنورد كه بدليل وجود صنايع و كارخانجات متعدد داراى جمعيت قابل ملاحظه اي از كاركَان است، قابل توجيه مى باشد. مطالعه

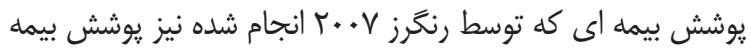
تأمين اجتماعى را Q9 درصد كَزارش كرده است (•r). در زمينه وجود عامل بيمارى همزمان در بسترى مجدد در يزوهش حاضر به لحاظ آمارى ارتباط معنى دارى بدست نيامده در برد حاليكه مطالعات مشابه در سالمندان ارتباط معنى دارى را در اين

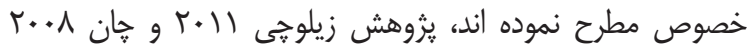
به دليل وجود ارتباط معنى دار در سالمندان با بيماريهاى همزمان ندان را عنوان نموده اند (T/،آ). استور نيز خطر نسبى معنى دارى در بروز بسترى مجدد از نظر وجود بيمارى همراه را كزارش كرد (بَا). از علل تفاوت نتايج يزوهش با مطالعات فوق را طول مدت مطالعه در تحقيقات ياد شده عنوان نمود كه يك ساله و بيشتر بوده است. در مطالعه اخير همجنين مشخص شد ميان بسترى شدن مجدد و سطح وابستخى ارتباط معنى دارى وجود دارد. همجنين بسترى مجدد باعث افزايش وابستخى بيمار به اطرافيانش شده، كه در مطالعه

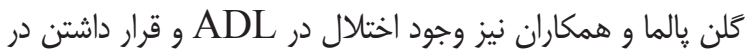
سطحى از وابستگى پِ از ترخيص از بيمارستان، ريسك بسترى

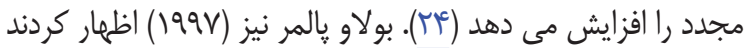

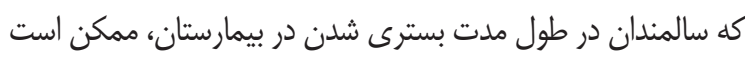
دجار وابستخى عملكردى، اختلال عملكرد شناختى، ناهنجارى هاى دي خلقى، وسوء تغذيه شوند (ها)). بررسى مطالعات در اين زمينه، حاكى

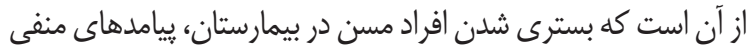
جسمى و شناختى فراوانى در بیى دارد. سالمندان بسترى به اقتضاى

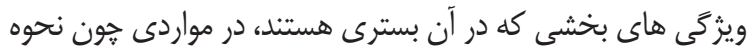

Riera A, Vazquez-Diaz JR, Duque-Gonzalez

B,Sarria-Santamera A. Risk factors for hospital readmissions in elderly patients: Asystematic review. QJM 2011;104: 63951.

4. Garcia-Perez L, Linertova R, LorenzoRiera A, Vazquez-Diaz JR, Duque-Gonzalez B,Sarria-Santamera A. Risk factors for 
hospital readmissions in elderly patients: Asystematic review. QJM 2011;104:639-51.

5. Arab M, Eskandar Z, Rahimi A, Pourreza A., Investigate the causes of readmission of patients at Tehran University of Medical SciencesHospital Quarterly, Summer 2012, Volume 9, Number 2-1 (Issue 34) Page.

6. Carlotta Franchi، AlessandroNobili، Daniela Mari‘Mauro Tettamanti،Codjo D.Djade, Luca Pasina Risk factors for hospital readmission of elderly patients.January 2013 Volume 24, Issue 1, Pages 45-51.

7. Yam CH, Wong EL, Chan FW, Leung MC, Wong FY, Cheung AW, et al. Avoidable Re admission in Hong Kong - system, clinician, patient or social factor Hong kong med 2010 OCT:16 (5):383-9.

8. Dharmarajan, Kumar, et al. "Association of changing hospital readmission rates with mortality rates after hospital discharge." Jama 318.3 (2017): 270-278.

9. Elsamadicy, Aladine A., et al. "Post-operative delirium is an independent predictor of 30day hospital readmission after spine surgery in the elderly ( $\geq 65$ years old): A study of 453 consecutive elderly spine surgery patients." Journal of Clinical Neuroscience 41 (2017): 128-131.

10. Khera, Rohan, et al. "Comparison of readmission rates after acute myocardial infarction in 3 patient age groups (18 to 44,45 to 64 , and $\geq 65$ years) in the United States." The American journal of cardiology 120.10 (2017): 1761-1767.

11. Comette P, D'Hoore W, Malhomme B, Van Pee D, Meert P,Swine C. Differential risk factors for early and later hospital readmission of older patients. Aging Clin Exp Res.2005;17:322-8.

12. Coleman EA, Parry C, Chalmers S, Min S. The Care Transitions Intervention .Results of a randomized controlled trial. Arch Intern Med 2006;166:1822-8.
13. Zanochi, M., Maero, B., Martinelli, E., Cerrato, F., Corsinovil, L., Gonella, M., Ponte, E., Luppino, A., Margolcci, A. \& Molaschi, M. 2006. Early re-hospitalization of elderly people discharged from a geriatric ward. Aging clinical and experimental research, 18, 6 .

14. Haideri- A. Prevalence and factors associated with hospital readmission in patients referred for heart Knowledge Horizon, Journal of Gonabad University of Medical Sciences. (Volume 17, Number 2, Summer of 1390.

15. Mirzaeyan, S., Iezady, A., Ebrazeh, A. \& Mohammady, P. 2014. Prediction of readmission based on LACE index in medical ward of Hajar hospital of Shahrekord. Journal of Clinical Nursing and Midwifery, 3.

16. Farshidi H. Most prevalent causes of rehospitalization in ischemic heart diseases. J Hormozgan Medicine 2004; 8 (2): 67-71. [In Persian].

17. Chin M, Goldman L. Factors contributing to the hospitalization of patients with congestive heart failure. Ame J Pub H 1997; 87 (4): 643-648.

18. Mir Mohammad Khani M, The Survey of Distribution, Causes and Costs of Hospitalization of Old Patients Supported by Medical Services Insurance Organization in Damghan, [MPH Dissertation]. Tehran. Tehran University of Medical Sciences, 1385 [in Persian].

19. Mould-Quevedo JF, García-Peña C, Contreras- Hernández I, Juárez-Cedillo T, Espinel-Bermúdez C,Morales-Cisneros $\mathrm{G}$, et al. Direct costs associated with the appropriateness of hospital stay in elderly population.BMC Health Services Research. 2009;9 (151).

20. Rangraz Jaddi F, Insurance Coverage of the Elderly Hospitalized in Kashan Shahid 
Beheshti Hospital, Abstract book, National Congress of Geriatrics \& Gerntology, 2007 [in Persian].

21. Ziluchi- M,H, Pour Reza Abolghasem, Akbari Feiz A ..., Rahimi Saleani Abbas. A survey on the pattern of consumption of elderly hospital services in teaching hospitals of Kashan University of Medical Sciences. Hospital. 1390; 10 (1): 63-70.

22. Chan MF. A study on investigating unplanned readmission patterns. J clin nurs 2008; 17(16): 2164-2173.

23. Steuer J, Blomqvist P, Granath F, Rydh B, Ekbom A, Ulf F. Hospital readmission after coronary artery bypass grafting: are women doing worse? J Ann Thorac Surg 2002; 73 (5): 1380-1386.

24. Glen DePalma, MS Huiping $\mathrm{Xu}, \mathrm{PhD}$ Kenneth E. Covinsky, MDBruce A. Craig, PhD Eric Stallard, ASA Joseph Thomas, III, PhDLaura P. Sands, PhD Hospital Readmission Among Older Adults Who Return Home With Unmet Need for ADL Disability The Gerontologist, Volume 53, Issue 3, 1 June 2013, Pages 454-461 -02 August 2012.

25. Palmer RM, Bolla L. when your patient is hospitalized: tips for primary care physicians. Geriatrics 1997; 52 (9):36-42, 47.

26. Hughes M, Heycox K. Promoting reflective practice with older people: Learning and teaching strategies.Australian Social Work 2005; 58 (4): 34 